\title{
Farmer participatory pond based cage aquaculture for raising fish seed in South Garo Hills, Meghalaya, India
}

\author{
S. K. DAS, T. SAMAJDAR, AMIT DAS AND M. ISLAM \\ ICAR-Research Complex for North-Eastern Hill Region, Umroi Road, Umiam - 793 103, Meghalaya, India \\ e-mail: tsamaj@rediffmail.com
}

\begin{abstract}
Fingerling sized fish seeds are always in great demand for any type of aquaculture operations. The paper highlights the results of a maiden study undertaken to popularise pond based cage culture for raising fingerling sized fish seed aimed at stocking quality fish fingerlings for augmenting fish production in the Garo Hills of Meghalaya. A farmer participatory study was undertaken for raising fry to fingerling sized fish seeds of 3 fish species viz., silver carp (Hypophthalmichthys molitrix), gonius (Labeo gonius) and common carp (Cyprinus carpio) in pond based cages during September-November 2011. Fry sized fishes of these species were reared in locally made bamboo-net cages $(2 \times 1.5 \times 2 \mathrm{~m})$ at different stocking densities. The primary objective was to increase the survival rate and observe the comparative growth rate of different species under

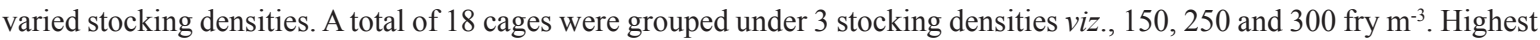
survival rate was observed at a stocking density of $150 \mathrm{fry} \mathrm{m}^{-3}$ for all the three species. Among the three species, silver carp demonstrated the highest survival rate at all the stocking densities. In terms of growth, better performance was observed with stocking density of 250 fry $\mathrm{m}^{-3}$ for all species.
\end{abstract}

Keywords: Cage culture, Carp, Fish seed rearing, Pond

Fisheries sector plays an important role in the socio-economic development of a country. According to the Department of Animal Husbandry, Dairying and Fisheries (DADF), Govt. of India, the total fish production during 2014-15 was 10.16 million $t$ with a contribution of 6.51 million $t$ from inland sector and 3.65 million t from marine sector respectively (DADF, 2016). India is also a major producer of fish through aquaculture and ranks second in the world after China. The sector contributed about $0.9 \%$ to national gross domestic products (GDP) and $5.17 \%$ to agricultural GDP during 2014-15 (DADF, 2015).

The availability of quality seed is prerequisite for rapid expansion and growth of aquaculture. While the country has witnessed a rapid growth in fish and fish seed production, the status of the state Meghalaya in the north-eastern region of the country remained stagnant despite its vast inland fishery resources in the form of rivers, reservoirs, lakes, ponds and an average rainfall of $1200 \mathrm{~mm}$. The available data with all its limitations shows about $4500 \mathrm{t}$ of fish production during 2011-12 that has not increased since 1990s. The production of fingerlings shows a slightly increasing trend only in recent years. The number of fingerlings produced in Meghalaya increased from 10 lakhs in 2006-07 to 29.6 lakhs in 2010-11 (Anon., 2012). The per capita annual consumption of fish during 2004-05 was $6.425 \mathrm{~kg}$ in Meghalaya as against $7.096 \mathrm{~kg}$ at the national level (NSSO, 2006). Considering the same level of consumption for 2011, the total consumption in the state is estimated to be $19,000 \mathrm{t}$ and thus the gap between demand and supply is 14,500 t. The huge gap in supply and demand of fresh fish in the locality resulted in transport of fish from outside the state.

Considering the above scenario, it is of utmost importance to harness the potential of the natural resources of the state and to create mass awareness about the multifarious benefits of fish culture among the people, particularly in the rural areas such as the South Garo Hills District. Considering the non-vegetarian food habit of local people (90\% are Garo tribes of which $98 \%$ are non-vegetarians), fish serves as an important source of animal protein in their diet. Due to several factors, the fish population in the open water bodies (rivers, beels, reservoirs and lakes) in the district has declined to a large extent over the past few years. Hence the production of fish is largely restricted to small ponds (0.1-0.2 ha). However, due to its hilly terrain, number of such ponds is also limited (approximately, one pond per 10 households). Fish culture in the district is extensive to semi-intensive in nature with zero to minimum management. In our survey, production of fish from such ponds was found to range from 500 to $1500 \mathrm{~kg} \mathrm{ha}^{-1}$, which is very low compared to the national average. Most often fish farmers of the South Garo Hills District rely on fish seed vendors of neighbouring states 
viz., Assam, West Bengal and bordering Bangladesh. These vendors normally sell fry sized fish seeds and most of them die when they are stocked in ponds by the farmers. Further, these tender fish seeds are highly prone to mortality and predation by aquatic animals. In general, fingerling sized fish seeds measuring 6-10 cm length is ideal for fish culture. Since the recommended size of fish fingerlings are not readily available to enhance fish production, an effort has been made in this preliminary study to raise fingerling sized fish seeds in low cost pond based cages in the farmer participatory mode.

Cage fish culture ensures constant circulation of water through the meshes of the cages, relatively less accumulation of metabolic wastes and constant renewal of oxygenated water within the cage. This enables higher stocking density and consequently, higher production per unit volume than in ponds. The raising of fish fry in cages also reduces the risk of predation by carnivorous fish and other predators. Besides, problem of conventional disputes regarding fish culture in multi owned or community water bodies could be overcome by cage fish culture system (Hasan et al., 1982). Thus pond based cage fish seed rearing was undertaken to demonstrate the feasibility of cage culture where an average survival percentage of about 30\% has been reported (Anon., 2006).

The study was carried out as a part of the Sibbari Cluster of National Agricultural Innovation Project (NAIP) component - 3 which comprised 11 villages spanning geographic area of about $25 \mathrm{~km}^{2}$ with about 505 households under Gasuapara CD Block of South Garo Hills District in Meghalaya. Trials on cage culture were carried out with a total of 18 cages installed one each in the ponds of 16 farmers and two cages in a community tank selected randomly from seven adopted project villages namely Defiluapara (4 cages), Mandangre (3 cages), Dima Chigitchak (3 cages), Baigonkona

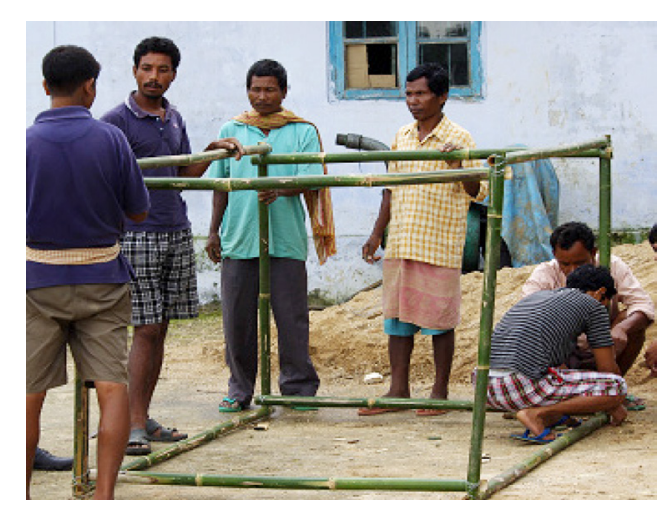

(a)
( 2 cages), Kongkona (3 cages), Batabari (2 cages) and Onajara (1 cage) under NAIP Sibbari cluster. Eighteen farmers responsible for their ponds or with management rights of the ponds were trained on bamboo cage manufacturing (Fig. 1) with inner nylon net lining at the Indian Council of Agricultural Research (ICAR) Complex for North-Eastern Hilly Region located at Barapani and at Krishi Vigyan Kendra (KVK), Tura, Meghalaya. Cages were locally made by farmers and installed in the 17 ponds/tank. Each cage had rigid bamboo frames with six sides made up of split bamboo and inner nylon lining with fine mesh. The size of each rectangular cage was $2 \times 1.5 \times 2 \mathrm{~m}$ which facilitated partial submersion of cages in the water. Data on the approximate survival rate of fish fry in open water, type of ponds and type of farming under traditional methods were collected by personal interview with all the farmers involved. Actual measurement of pond area and depth was carried out manually. Water quality testing kits were used to test selected water quality parameters during the study. The physico-chemical characteristics recorded are given in Table1.

The study was carried out for 3 months period (September - November 2011) with 3 species viz., silver carp (Hypophthalmichthys molitrix), gonius (Labeo gonius) and common carp (Cyprinus carpio). Fry sized fishes of these species were reared in cages at different stocking densities. The participating tribal farmers were advised to feed the fishes once a day with a mixture of locally available rice bran and mustard oil cake at 1:1 ratio. The feed was allowed to seep slowly from a submerged feeding tray positioned centrally in the cage in the surface/subsurface water. Although recommendation was made to feed the fishes at $10 \%$ of the total biomass present in the cage in addition to the already available natural fish food in the pond ecosystem, accurate data

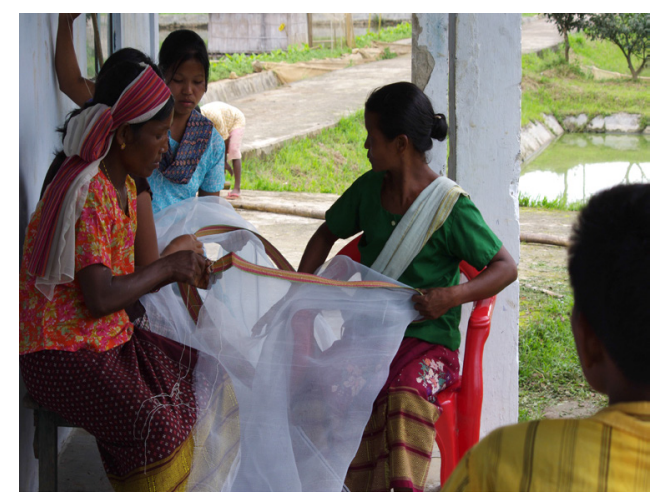

(b)

Fig. 1. On the job training on cage fabrication imparted to participating farmers at ICAR Research Complex for NEH Region, Barapani, Meghalaya 
Table 1. Physico-chemical characteristics of the pond water under cage trial

\begin{tabular}{|c|c|c|c|c|c|c|c|}
\hline $\begin{array}{ll} & \text { Village } \\
\text { Parameters }\end{array}$ & Defuliapara & Mandangre & Dima Chigitchak & Baigonkona & Kongkona & Batabari & Onajara \\
\hline $\begin{array}{l}\text { Elevation (meters above sea } \\
\text { level) }\end{array}$ & 28 & 27 & 32 & 11 & 17 & 15 & 24 \\
\hline Average pond area $\left(\mathrm{m}^{2}\right)$ & 580 & 756 & 592 & 410 & 390 & 610 & 498 \\
\hline Mean water depth (m) & 1.3 & 1.2 & 1.0 & 0.9 & 0.9 & 1.0 & 1.0 \\
\hline Water temperature $\left({ }^{\circ} \mathrm{C}\right)$ & $17.1-25.0$ & $17.0-25.4$ & $18.3-26.2$ & $18.5-25.7$ & $18.0-26.1$ & $18.0-27.2$ & $17.2-25.6$ \\
\hline $\begin{array}{l}\text { Dissolved oxygen at } \\
\text { surface }\left(\mathrm{mg} \mathrm{l}^{-1}\right)\end{array}$ & $6.5-10.5$ & $7.0-12.0$ & $6.2-10.5$ & $7.0-10.0$ & $6.5-11.0$ & $7.2-10.0$ & $7.0-12.0$ \\
\hline $\mathrm{pH}$ & $6.3-7.5$ & $6.5-7.8$ & $6.0-7.2$ & $5.9-7.0$ & $6.1-7.2$ & $5.8-7.0$ & $6.0-6.8$ \\
\hline Alkalinity (ppm) & $30.0-36.5$ & $33.0-36.0$ & $30.0-37.5$ & $28.0-32.0$ & $30.1-38.7$ & $29.5-35.8$ & $30.0-37.5$ \\
\hline Seasonal/perennial & Perennial & Perennial & Perennial & Seasonal & Perennial & Seasonal & Perennial \\
\hline
\end{tabular}

on feeding rate from the participatory tribal farmers could not be collected as majority were either illiterate or semi-literate to record the required information. A total of 18 cages were grouped under 3 stocking densities viz., 150,250 and 300 fry $\mathrm{m}^{-3}$. The total number of fish seed in each cage varied between 400 and 800 . Total length (TL) of the fish $(\mathrm{cm})$ was considered as size parameter in our study and the size at stocking was 4.95, 3.12 and $3.94 \mathrm{~cm}$ for silver carp, gonius and common carp respectively. In the absence of actual data on feeding rate, feed consumption and percentage of decomposition rate, it was assumed that the fishes were fed to satiation. Final length was measured at the end of 3 months and the fishes were released in the same ponds after they attained advanced fingerling stage. Survival rate of fish was calculated based on random sampling method with displacement where a standard beaker of unit size was used for scooping out fish after lifting the inner nylon netting. The number of each species per beaker was counted and after a significant number of samplings, multiplying the number with total number of scoopings gave the total number of each species survived in each cage. For economic analysis, only the wages of family labour for cage fabrication, maintenance of cage as well as feeding and cost of fish fry were considered. The net income was estimated based on market price equivalence to the given size of fish. Fig. 2(a-c) shows different stages during the rearing of fish seed in pond-based cages.
All fish species recorded high survival in the cages than in the open water bodies. Highest survival rate was observed at a stocking density of 150 fry $\mathrm{m}^{-3}$ for all species. A comparative survival rate has been highlighted in the Fig. 3a. Among the three species, silver carp demonstrated the highest survival rate in all the stocking densities (Fig. 3b 4). In terms of growth, better performance was observed with stocking density of 250 fry $\mathrm{m}^{-3}$ for all species. The growth achieved by all species under different stocking densities is presented in the Fig. 3.

The number of fish produced per cage and rate of fish survival per cage irrespective of stocking densities in different villages is given in the Table 2. Estimated net income (ENI) based on market price (market price per fingerling was assumed to be between ₹3 and ₹5 depending on the size of the fish and estimated net income was calculated based on market price equivalence (not actual values) per cage is also presented in Table 2.

The cage trials were carried out in existing unmanaged ponds of the farmers. Therefore, in the absence of actual data on fish survival in open system, absolute comparison of survival percentage could not be made between open water vs cage enclosure. However, it was observed that the survival rate was higher in the cages compared to farmer's practice irrespective of species and stocking densities, indicating the suitability of the method for achieving higher survival rate. Studies suggests that

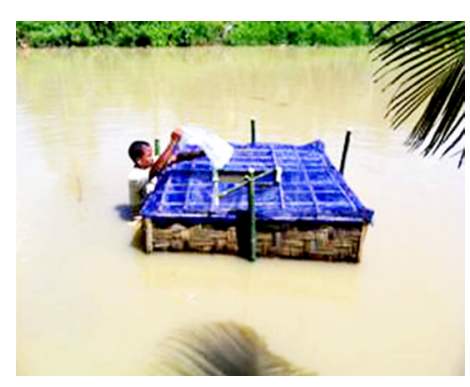

(a)

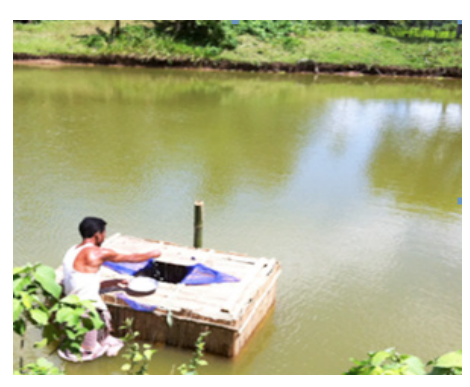

(b)

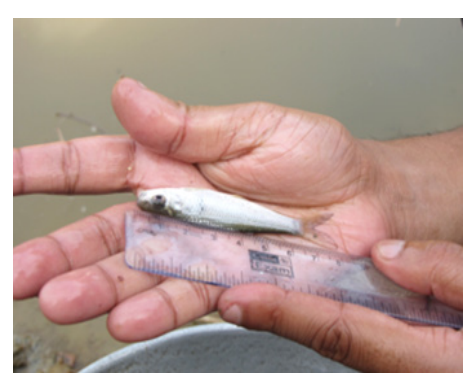

(c)

Fig. 2. Stages during pond based cage fish rearing demonstration in Sibbari Cluster 

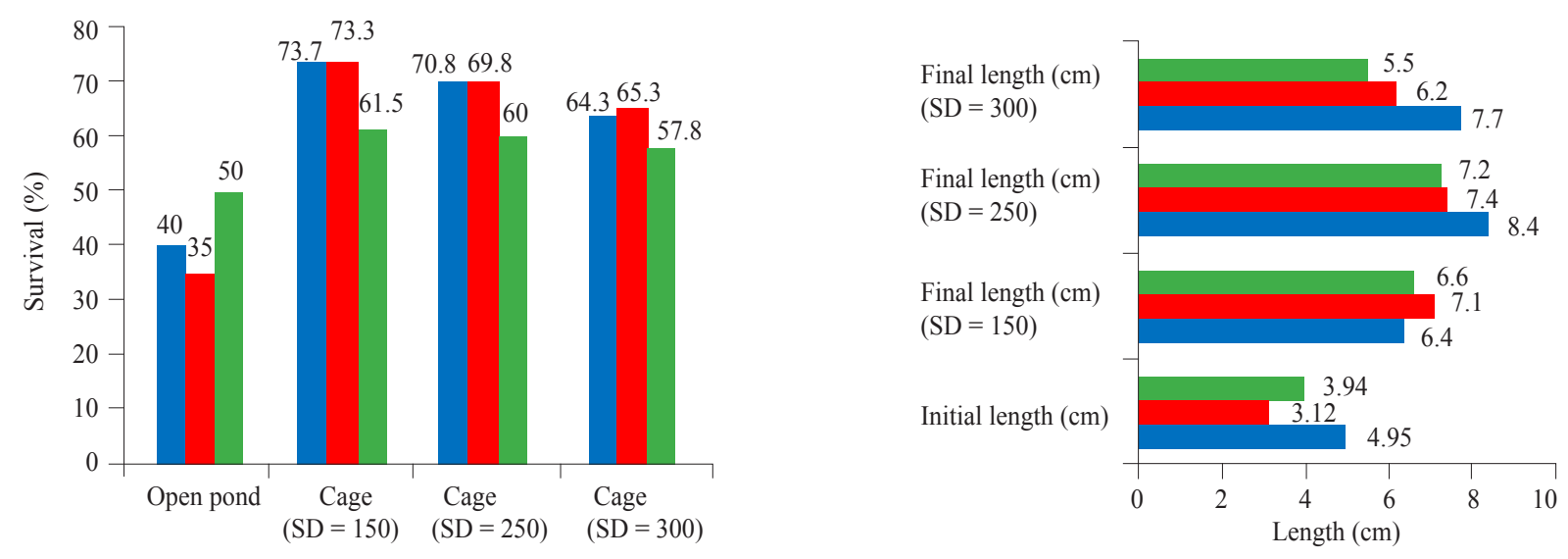

- Silver carp, Gonius, Common carp, SD: Stocking density

(a)

(b)

Fig. 3. Comparative (a) survival rate and (b) growth rate of silver carp, gonius and common carp during rearing in pond-based cages

Table 2. Average number of fingerlings produced, average survival rate and net income per cage-(village-wise)

\begin{tabular}{|c|c|c|c|c|c|c|c|}
\hline \multirow{2}{*}{ Village } & \multicolumn{2}{|c|}{ Silver carp } & \multicolumn{2}{|c|}{ Gonius } & \multicolumn{2}{|c|}{ Common carp } & \multirow[t]{2}{*}{ ENI/C (₹.) } \\
\hline & ANFP/C & $\mathrm{ASR} / \mathrm{C}$ & ANFP/C & $\mathrm{ASR} / \mathrm{C}$ & ANFP/C & $\mathrm{ASR} / \mathrm{C}$ & \\
\hline Defuliapara & 244 & 70 & 190 & 67 & 110 & 58 & 1820 \\
\hline Mandangre & 280 & 65 & 210 & 69 & 140 & 56 & 1740 \\
\hline Dima chigitchak & 250 & 67 & 240 & 65 & 129 & 62 & 1670 \\
\hline Baigonkona & 180 & 68 & 210 & 67 & 80 & 55 & 1200 \\
\hline Kongkona & 260 & 67 & 232 & 71 & 128 & 61 & 1450 \\
\hline Batabari & 220 & 71 & 198 & 70 & 170 & 62 & 1500 \\
\hline Onajara & 198 & 70 & 205 & 69 & 117 & 60 & 1300 \\
\hline
\end{tabular}

$\mathrm{ANFP} / \mathrm{C}=$ Average number of fingerling produced per cage; $\mathrm{ASR} / \mathrm{C}=$ Average survival rate per cage; $\mathrm{ENI} / \mathrm{C}=$ Estimated net income per cage

fish culture in cages could be developed by improving stocking density, feeding methods, appropriate selection of species and regulating the culture cycle for maximum profitability (Sodkin, 1977). Higher survival rate was observed at a stocking density of 150 fry $\mathrm{m}^{-3}$ compared to higher stocking densities which could be attributed to lesser competition for food and space between the fish. Higher survival rate recorded for silver carp could be due to the higher abundance of phytoplankton in the surface/subsurface water, as silver carp is primarily a surface feeder, feeding on phytoplankton. In the absence of control groups, the effect of feed on the growth or survival rate could not be quantified. The estimated net income per cage varied from village to village. Although the income generation is meager in small scale operation, it is justified considering the total number of fingerlings produced. It is envisaged that with large-scale operation and improved feeding, the economic returns may be improved further. Otubusin (1987) opined that the lack of nutritionally adequate and low-cost feed has always been one of the constraints to the successful practice of cage fish culture in many developing countries. Although cost of feeding may account for half of the production cost in intensive cage culture (Coche, 1979), much higher growth rate is likely to compensate it. However, considering the non-availability of commercial feed in the remote locations, survival is more immediate priority than faster growth and hence a semi-intensive approach seems to be more appropriate.

Cage culture presently being an intensive aquaculture method is largely restricted to highly skilled farmers and in places with supplies of adequate commercial feed. However, a maiden effort has been made through this farmer participatory study to demonstrate low cost pond based cage culture for improving survival and growth of juvenile fish in the Garo Hills of Meghalaya with encouraging results. Nursery rearing of fish fry has always been a very challenging task due to higher percentage of mortality. With multiple cages in the same pond and by better pond management practices, the farmers could realise higher production and returns. In the absence of nursery ponds, pond based cage culture system can serve as one of the alternatives to increase the survival percentage and growth of fish fry enabling the rural farmers to stock fish ponds with quality fish fingerlings for augmenting fish production in the region. 


\section{References}

Anon. 2006. Fish farming and technologies for the North-eastern region - Pond to plate. Indian Council of Agricultural Research, Krishi Bhawan, New Delhi, 87 pp.

Anno. 2012. Meghalaya State Aquaculture Mission - From dependency to self sufficiency. Fish Farmer Development Agency, Department of Fisheries, Government of Meghalaya, Shillong, $02 \mathrm{pp}$

Coche, A. G. 1979. A review of cage fish culture and its application in Africa. In: Pillay, T. V. R. and Dill, W. A. (Eds.), Advances in aquaculture. Fishing News Books, Farnham, Surrey, p. 428-441.

DADF 2015. Annual report 2014-15. Department of Animal Husbandry, Dairying and Fisheries, Govt. of India

DADF 2016. Annual report 2015-16. Department of Animal Husbandry, Dairying and Fisheries, Govt. of India
Hasan, M. R., Aminul Haque, A. K. M., Aminul Islam, M. and Kaiser Khan, E. U. M. 1982. Studies on the effects of stocking density on the growth of Nile tilapia, Sarotherodon nilotica (Linnaeus) in floating cages. Bangladesh J. Fish., 2-5(1-2): 73-81.

NSSO 2006. Report of $61^{\text {st }}$ National Sample Survey 200405. National Sample Survey Organisation, Ministry of Statistics and Programme Implementation, Government of India.

Otubusin, S. O. 1987. Effects of different levels of blood meal in pelleted feeds on tilapia, Oreochromis niloticus production in floating cages. Aquaculture, 65: 263-266.

Sodkin, D. 1977. Fish cage culture in Indonesia, construction and management. Technical report of workshops on Aquaculture engineering, vol. III, 27 November, 1977. SEAFDEC Aquaculture Department Facility, Tigbauan, Iloilo, Philippines, p. 351-357. 